\title{
EMBEDDING JOURNALISTS in Military Combat Units: IMPACT ON NEWSPAPER STORY FRAMES AND TONE
}

By Michael Pfau, Michel Haigh, Mitchell Gettle, Michael Donnelly, Gregory Scott, Dana Warr, and Elaine Wittenberg

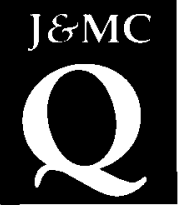

This investigation probed whether embedded journalist coverage of the first days of the 2003 U.S. invasion of Iraq produced print news coverage that was either more decontextualized in form or more favorable in tone. Embedded news coverage of the first days of Operation "Iraqi Freedom" was compared to nonembedded, so-called "unilateral" coverage; and print coverage of "Iraqi Freedom" was compared with the first days of U.S. ground operations in Operations "Enduring Freedom" and "Desert Storm." The results indicated that embedded journalists in Operation "Iraqi Freedom" produced news stories that featured more episodic frames, compared to both nonembedded reporters in "Iraqi Freedom" and overall coverage of Operation "Enduring Freedom." The results also revealed that, compared to nonembedded reporting, embedded print coverage of "Iraqi Freedom" was more favorable in overall tone toward the military and in depiction of individual troops, but this bias did not produce more positive overall coverage compared to recent conflicts.

The U.S. military took an unprecedented step in military/news cooperation during the 2003 invasion of Iraq (Operation "Iraqi Freedom") by adopting a strategy of systematically embedding journalists in combat units. The military defines an embed "as a media representative

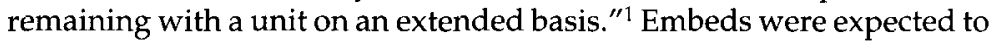
"live, work and travel as part of the units with which they are embedded to facilitate maximum, in-depth coverage of U.S. forces in combat and related operations." 2 The strategy of embedding journalists in combat units was "spearheaded" by Victoria Clark, a former public relations executive who served as senior spokesperson for Secretary of Defense

JEMC Quarterly Vol. 81, No. 1 Spring 2004 $74-88$ C2004 AEJMC
Michael Pfau is professor and chair of the Department of Communication at the University of Oklahoma where Michel Haigh and Elaine Wittenberg are doctoral students. Mitchell Gettle, Michael Donnelly, Gregory Scott, and Dana Warr were students in the Department of Defense Joint Course in Communication at the University of Oklahoma when this study was conducted. All are in military public affairs: MSgt. Gettle with the $436^{\text {th }}$ Airlift Wing, Dover AFB, DE; Maj. Donnelly with American Forces Network, Europe; lst Lt. Scott at the Marine Corps Air Station, Miramar; and Petty Officer $2^{\text {nd }}$ Class Warr with the Seventh District PADET, Jacksonville, FL. 
Donald Rumsfield at the outset of "Iraqi Freedom." ${ }^{3}$ The question posed in this investigation is whether the practice of embedding produces print news coverage that is either more decontextualized in form or more favorable in tone.

The practice of embedding journalists in military units is not new. It has been used on a limited basis in previous conflicts. However, the scope of embedding in Operation Iraqi Freedom was "massive," involving more than 600 U.S. and foreign journalists ${ }^{4}$ at a cost to participating news outlets of about $\$ 100$ million. ${ }^{5}$ Journalists "have never...worked alongside U.S. military units...in such numbers [or] in such an organized fashion." ${ }^{16}$ The scale of embedding employed in Operation Iraqi Freedom was "unprecedented for the opening stages of a conflict involving the United States. ${ }^{.7}$ It offered a first-hand, up-close view of combat missions that was unavailable to unilateral (unembedded) or pool reporters.

It is unclear what motivated Pentagon officials to take this step. In part, the decision to embed may have been defensive, a strategy to preempt opposition attempts to spread outright lies and misinformation about the U.S. operation. ${ }^{8}$ As Bryan Whitman, deputy assistant secretary of defense for media operations, noted: "We recognized early on that we needed to make truth an issue should there be a military campaign because Saddam Hussein was a practiced liar, a master of deception," and the only way to defend against that is through "objective third-party accounts from professional observers." ${ }^{\prime 9}$

The decision may have been motivated by the sincere desire of military officials to "facilitate access of national and international media to our forces." 10 Whitman continued: "We also believed Americans deserved to see exactly how well trained their military forces were, how dedicated and professional."11 Clark, the director of Pentagon public affairs at the outset of Operation "Iraqi Freedom," suggested both of these motivations. "People around the world got to see the U.S. military in a very real and compelling way...they saw the compassion with which they prosecuted this war."12 In either case, this more transparent approach constitutes a complete "about face" from recent military restrictions on journalist access to combat, which was a point of considerable contention during U.S. military operations in Grenada, Panama, and Afghanistan. ${ }^{13}$

Or, the Pentagon decision to facilitate journalists' access to combat operations may have been motivated by a conscious attempt to slant news coverage. The 1982 Falklands War between the United Kingdom and Argentina offered a precedent in embedding. In the Falklands War, the journalists embedded with British forces far from home "were completely reliant on the military, not only for access to the battle zone, but for food, shelter, protection, and transmission of their reports."14 This dependence "created an esprit de corps between the journalists and the military" that resulted in identification, even "camaraderie," with military forces, which may have played some role in the favorable news coverage of British forces that emerged from the conflict. ${ }^{15}$

Reaction of journalists to embedding was positive, but with the caveat that reporters must maintain perspective. Reporters appreciated the access to combat operations, which many thought would produce "a 
more complete picture" of the war than was available in recent U.S. conflicts. ${ }^{16}$ One reporter retrospectively praised embedding as "the most innovative aspect of coverage" of Iraqi Freedom, producing news coverage of the war that was "intimate, immediate, absorbing, almost addictive." 17

The caveat, that embedded journalists must maintain perspective, was perceived as a difficult challenge. The challenge of maintaining perspective involves two dimensions. First, there is the obvious danger that journalists could become too close to the fighting men and women they are covering. One reporter described embedding as "professionally treacherous," explaining that "There is a real danger of getting too close to your subject." 18 Another referred to embedding as producing a variation of the "Stockholm Syndrome," in which journalists become dependent for their own survival on the soldiers they are covering and, as a result, "become enamored" of them and "lose perspective." ${ }^{19}$ Second, there is the possibility that embedding might produce a narrow, decontextualized coverage of war. Embedding affords an "extremely deep, rich coverage of what's going on in a particular unit," ${ }^{20}$ what might be called "the minutiae of the conflict," 21 or "a little slice of grunt-level reality." ${ }^{22}$ A television news executive questioned how much embedded journalists saw, concluding that, "It's arguable they didn't see a doubledigit percentage of what happened." ${ }^{23}$ What is lost in such micro coverage is the big picture: "insight into the purpose and context" of individual missions within the context of the broader war. ${ }^{24}$

Unfortunately, the available evidence as to whether journalists maintained perspective in their coverage of Operation "Iraqi Freedom" is largely anecdotal, based on the personal opinions of journalists or academics. This investigation attempted to address both aspects of this question of journalist perspective. Specifically, the study probes whether embedded journalist coverage of the first days of the 2003 U.S. invasion of Iraq produced print news coverage that was either more decontextualized in form or more favorable in tone. Print news coverage of the first days of Operation "Iraqi Freedom" was compared to both: coverage of the first days of "Desert Storm," the start of ground operations in the 1991 Gulf War, and Operation "Enduring Freedom," the 2002 U.S. invasion of Afghanistan; and unilateral (unembedded) coverage of Operation "Iraqi Freedom." This investigation anticipated finding both biases (decontextualization and favorableness) in embedded coverage.

\section{Hypotheses}

The very nature of embedded coverage should produce more decontextualized coverage, which focuses on specific military units and personnel instead of overarching context and analysis. Journalists frame news stories; that is, they package stories and, in the process of doing so, give stories meaning. ${ }^{25}$ Framing is about the choices that journalists make in the reporting of stories. ${ }^{26}$ Journalists' choices, in turn, affect the way that stories are interpreted by consumers of news. ${ }^{27}$ As Price and Tewksbury explain, the way stories are packaged "systematically affect[s] how political events are perceived by the public. [Frames] alter the...considerations people use in forming their opinions. ${ }^{28}$ 
Although framing can be approached in a variety of ways, Iyengar describes two broad framing approaches that are particularly relevant to this investigation. He distinguishes episodic and thematic frames. ${ }^{29}$ "Episodic framing seeks to personalize issues," whereas "thematic framing presents collective or general evidence" about issues. ${ }^{30}$ Episodic frames are based on compelling exemplars; they "are essentially illustrative of issues." 31 Thematic frames provide more "in-depth, interpretive analysis." 32 They depict issues "more broadly and abstractly by placing them in some appropriate context-historical, geographical, or otherwise." ${ }^{33}$ Iyengar argues that television news relies more heavily on episodic instead of thematic frames for a number of reasons: perhaps the most important reason is the visual nature of the medium, which places a premium on individual exemplars; another reason is the reduced demand for reporter subject-matter expertise with use of episodic as opposed to thematic reports. ${ }^{34}$

This study argues that the nature of embedding reporters in combat units in war is a special circumstance that should produce episodic framing of news stories regardless of whether stories are carried via television or print. The reason is the intrinsic nature of embedding. Embedded reporters are attached to specific units for extended periods, literally isolated from the broader war. As Pentagon spokesperson Bryan Whiteman explained: "Embedding means living, eating, moving in combat with the unit that you are attached to....A reporter embeds for life," 35 meaning that, once attached, reporters are not permitted to change assignments. What an embedded reporter experiences is "a very narrow view of what's going on," 36 what one reporter termed "a snapshot." ${ }^{37}$ The problem is that individual embedded reporters lose context. They offer depth of coverage about their unit, but no broader context, what Kaplan characterized as "vertical depth but little horizontal scope." 38 He explains that: "Profound portraits of individual soldiers were rarely complemented by placing the various military operations in the context of a grand strategic view." 39 Murray and Scales maintain that news reports offered "little insight into the purpose and context of...missions." 40 Ledbetter notes that, "no single slice of the war can give you the big picture" $^{\prime 41}$ and, as a result, context and analysis were "largely missing" from many of the Operation "Iraqi Freedom" news reports. ${ }^{42}$ This is precisely what happened with embedded news reports during the Falklands War. Embedding "led to an emphasis on the minutiae of the conflict at the expense of the big picture." 43 Embedding inherently produces episodic news reporting; it is incapable of more. As one reporter commented about embedding during Operation "Iraqi Freedom": "Being so close to a particular unit made it nearly impossible to see the full scope of the war or its politics. ${ }^{44}$ Hence, this study predicts:

H1: Compared to nonembedded coverage, embedded journalist newspaper stories about the military, its units, and personnel are more episodic in nature.

Embedded coverage of the first days of Operation "Iraqi Freedom" should also produce print news coverage that is more favorable in tone, 
both toward the military generally and toward its personnel. This expectation is based on the fact that embedding, de facto, makes journalists members, albeit temporarily, of individual military units. As a result, journalists will come to know the troops they are covering and, to some degree, internalize the values of the military unit they are embedded in.

Knowing the troops they are covering can lead to bias in news coverage of the military and its personnel. Social Penetration Theory offers an explanation of how interpersonal relationships unfold and the implications of developing relationships. ${ }^{45}$ Relationships develop through contact, which makes possible increasing self-disclosure. Self-disclosure involves sharing of information about oneself with another, which facilitates social penetration. ${ }^{46}$ Relationships begin with relatively limited breadth and depth but, through increasing self-disclosure, develop in intensity and intimacy. ${ }^{47}$ This process normally requires time, but when military units engage in combat, termed "hot conditions," the bonding of personnel accelerates. ${ }^{48}$ Assuming that participants in a relationship experience a mutually favorable reward-cost balance, ${ }^{49}$ close contact with another person triggers a spiraling process, one in which increasing levels of self-disclosure elicit more liking, and greater liking, in turn, produces even more self-disclosure. ${ }^{50}$ An inevitable byproduct of social penetration is relational trust, ${ }^{51}$ which can bias perceptions. ${ }^{52}$

If journalists internalize the values of the military unit they are embedded in, the potential for biased news coverage increases. The organizational culture metaphor offers an explanation for how this can happen. Organizational culture consists of "a pattern of shared basic assumptions that...[are] taught to new members as the correct way to perceive, think, and feel...."53 As such, it imposes conventions, which invite conformity to the values that are unique to the organization's culture. ${ }^{54}$ Organizational culture "serves as a mechanism of social control." 55 As Beyer, Hannah, and Milton explain, "when people adopt identities that tie them to a particular group of people, they become more susceptible to the ideas and feelings generated within that group." 56

Pacanowsky and O'Donnell-Trujillo describe enculturation as the process in which the members of an organization "acquire the social knowledge and skills necessary to behave as component members." 57 Enculturation occurs in all organizations, but its effects are far more pronounced in military organizations, especially when confronting lifethreatening situations. In these circumstances, "there is a strong need for a so-called collective mind." 58

But would the process of enculturation affect embedded reporters assigned to military units for a short period? We think so, especially because of the combat conditions. Some degree of acceptance of the values of military culture is essential in embedding. For example, embeds, just like the military personnel they are serving with, must submit to military commands or place lives in jeopardy. To commence the process of enculturation, the military encouraged American journalists to train in military bootcamps before embedding; 238 journalists did so. ${ }^{59}$ For these and other embeds, the intensity of experiencing combat further facilitated enculturation. ${ }^{60}$ As Soeters explains, "In general, the organiza- 
tion-in-action is characterized by 'swift trust," which is a manifestation of bonding among team members." He adds: "Swift trust is more likely to occur when uncertainty is high and the situation is unfamiliar and dangerous. ${ }^{\text {61 }}$ In essence, journalists embed both in a military unit and its culture: the two are virtually inseparable. The process of enculturation in combat conditions ensures that, to some degree, embedded journalists will be affected by a military unit's values, including: "shared meaning, shared understanding, and shared sense making." 62

There is anecdotal evidence that embedded journalists developed personal relationships with the troops they covered and that they partially internalized the values of the military units they were assigned to. One embedded reporter described the process of journalists becoming combatants as "professionally treacherous. You are sleeping next to the people you are covering. Your survival is based on them."63 Another correspondent proclaimed: "We absolutely want our unit to be successful. Are we are emotionally invested? We are. We know these people."64 As a result, TV embeds often used the pronoun "we" in their stories of the U.S. march to Baghdad, "almost sounding as if they were fellow soldiers." 65 Thompson argues that this outcome was inevitable. "When you are part of the troops that you are going in with, these are your fellow human beings. You are being potentially shot at together, and I think that there is a sense that you are becoming part of that group in a way that a journalist doesn't necessarily want to be." 66

Did this produce bias? It was charged that "feelings of camaraderie $^{\prime \prime}$ affected objectivity during the Falklands War. A British journalist asserted that the desire to please the military and friendliness with individual soldiers can affect journalist independence, imposing a form of "self- censorship." 67 Morrison and Tumber said that there was "no escaping the military's embrace." They explain: "It was not just a question of sharing the moods of the troops through shared experience, but of actively beginning to identify with them...." ${ }^{16}$ This investigation anticipated more favorable print news coverage of the first days of Operation "Iraqi Freedom:"

H2: Compared to nonembedded coverage, embedded journalists produce more positive newspaper stories about (a) the military generally, and (b) its personnel.

\section{H3: Compared to coverage of Operations "Desert} Storm" and "Enduring Freedom," newspaper stories about Operation "Iraqi Freedom" manifest more positive bias toward the military.

To test the study's predictions, we conducted a content analysis of newspaper coverage of ground operations during the first five days of Operation "Iraqi Freedom" (20 to 24 March 2003), Operation "Enduring Freedom" (7 to 11 October 2001), and Operation "Desert Storm" (24 to 28 February 1991). ${ }^{69}$ The newspapers chosen for analyses were the New York Times, Washington Post, Los Angeles Times, and Chicago Tribune. The New 
York Times and Washington Post were chosen because of their national influence. Both exert considerable influence in political and military circles and both are "newspapers of record" in that they shape the agendas of other newspapers. The Los Angeles Times and Chicago Tribune were chosen because of their influence in the West and Midwest, respectively, thereby providing geographical balance.

The analysis focused on newspaper articles about military combat operations contained within the "national," "international," and "local" sections, including the front page of the paper. Complete articles were used in the analysis.

The unit of analysis was each article $(n=291)$. Four Department of Defense public affairs personnel, who were enrolled in a communication course at a Midwestern university, conducted the content analysis. Coding norms were established during a one-hour training session using articles about combat operations that were published outside of the fiveday window of the investigation. Researchers were paired for coding. Intercoder reliability was computed on the first 20 articles coded by each pair using Holsti's formula of the ratio of agreement among coder pairs, ${ }^{70}$ a simple and appropriate reliability measure. ${ }^{71}$ Intercoder reliability ranged from .875 to 1.0 across variables. ${ }^{72}$

The study featured two independent variables: reporter status and the particular war. Reporter status was coded based on information provided in each article as embedded, nonembedded (termed "unilateral" during Operation Iraqi Freedom"), and unknown. As noted, the wars examined were Operation "Iraqi Freedom," Operation "Enduring Freedom," and Operation "Desert Storm."

The investigation featured three dependent variables. Overall tone of coverage about the military was assessed using a global attitude measure consisting of six 7-interval scales, including: negative/positive, foolish/wise, worthless/valuable, unacceptable/acceptable, bad/good, and unfavorable/favorable. The measure was developed in the 1970s and employed in many studies of public institutions. ${ }^{73}$ Depiction of the trustworthiness of troops covered in news reports was assessed using a 4 -item version of the Individualized Trust Scale (ITS), which was initially developed by Wheeless and Grotz. ${ }^{74}$ The abbreviated version of the ITS has been employed in past research with good reliability ratings. ${ }^{75}$ The 4 , 5-interval items included: dishonest/honest, untrustworthy/trustworthy, deceptive/candid, and insincere/sincere. Finally, a single 5-interval scale was employed to measure the extent to which an article embodied episodic framing.

This investigation explores whether embedded journalist coverage of the first days of Operation "Iraqi Freedom" produced qualitatively different coverage, news reports that were more decontextualized in form and more favorable in tone. To assess the study's predictions, a series of one-way ANOVAs were computed: three examining the impact of journalist status (embedded, nonembedded, and unknown) on each of the three dependent variables, and three assessing the impact of the specific conflict ("Iraqi Freedom," "Enduring Freedom," and "Desert 


\section{TABLE 1}

Tendencies in Frames and Tone of Newspaper Stories as a Function of Journalist Status

Journalist Status:

Dependent Variable Embedded Nonembedded Unknown

STORY FRAMES

\begin{tabular}{|c|c|c|c|}
\hline Episodic $M$ (s.d.) & $4.56^{\mathrm{a}}(0.80)$ & $2.82(1.47)$ & $3.60(1.41)$ \\
\hline & $(n=93)$ & $(n=156)$ & $(n=34)$ \\
\hline
\end{tabular}

TONE OF COVERAGE

Overall Tone $M$ (s.d.)

Trust of Troops $M$ (s.d.) $4.27^{\mathrm{a}}(0.71)$

$$
(n=94)
$$

$4.66^{\mathrm{a}}(0.60)$

$$
(n=92)
$$

$$
3.42(0.88)
$$

$$
(n=32)
$$

$(n=21)$

Note: Framing was assessed using 5-interval scales to determine the extent to which an article's frame was more or less episodic. Higher scores indicate more episodic story frames. The tone of coverage was assessed using two scales: overall tone was measured using 7 -interval scales, and trust of individual troops depicted in stories was measured using a 5-interval metric. In all cases, higher scores indicate more positive treatment of the military.

${ }^{a}$ Significant compared to the average of nonembedded and unknown stories at $p<.01$.

Storm") on each of the dependent measures. Significant ANOVA results were followed up with planned comparisons, using Dunn's multiple comparison procedure, to assess predicted effects and Scheffe post-hoc tests to examine mean differences for any unpredicted effects. Journalist status results are shown in Table 1; conflict means are depicted in Table 2.

$\mathrm{H} 1$ predicted that, compared to nonembedded coverage, embedded journalist newspaper stories about the military, its units, and personnel are more episodic in nature. The one-way ANOVA revealed a significant main effect for reporter status on episodic framing $\left(F_{2,280}=\right.$ $53.90, p<.01)$. Planned comparisons indicated that embedded journalists produced news reports that manifest more episodic frames than nonembedded or unknown reporters $\left(F_{1,280}=48.32, p<.01\right)$. Thus, H1 was supported.

H2 posited that embedded coverage of Operation "Iraqi Freedom" would be more favorable in tone, both toward the military generally and toward its personnel. One-way ANOVAs revealed significant main effects on the dependent variables of overall tone of coverage $\left(F_{2,268}=\right.$ $32.42, p<.01)$ and depiction of the trustworthiness of troops $\left(F_{2,181}^{2,268}=\right.$ $19.40, p<.01$ ). Subsequent planned comparisons indicated that embedded journalists produced more positive news reports about the military than nonembedded or unknown reporters, both in their overall tone 


\section{TABLE 2}

Frame and Tone of Newspaper Stories across Recent U.S. Military Engagements

Military Engagement:

Dependent Variable

"Iraqi Freedom" "Enduring Freedom" "Desert Storm"

Episodic Framing $M(S D)$

Overall Tone $M(S D)$ $3.77^{\mathrm{a}}(1.46)$

$(n=128)$

$3.70(0.93)$

$(n=120)$
2.88 (1.43)

$$
(n=70)
$$

$(n=67)$
$3.58(1.50)$

( $n=85)$

$3.90^{\mathrm{b}}(0.95)$

$(n=84)$

Note: Framing was assessed using 5-interval scales to determine the extent to which an article's frame was more or less episodic. Higher scores indicate more episodic story frames. Overall tone of coverage of the military was measured using 7-interval scales. Higher scores indicate more positive depiction of the military.

a Significant compared to the average framing of newspaper stories from operations "Enduring Freedom" and "Desert Storm" at $p<.01$.

b Significant compared to the tone of stories from operation "Enduring Freedom" at $p<.05$.

$\left(F_{1,268}=44.00, p<.01\right)$ and in their depictions of individual troops $\left(F_{1,181}=11.83, p<.01\right)$. This pattern of results supports $\mathrm{H} 2$.

$\mathrm{H} 3$ predicted that, because of the extensive use of embedded reporting during Operation "Iraqi Freedom," that war's coverage would be more positive toward the military than coverage of "Desert Storm" and "Enduring Freedom." The one-way ANOV As indicated a significant effect on the dependent measure of overall tone of coverage $\left(F_{2,268}=3.67\right.$, $p<.05)$, but not on trustworthiness of troops $\left(F_{2,181}=0.52, p=.595\right.$, observed power $=.135$ ). However, as Table 2 reveals, overall tone of coverage in "Iraqi Freedom" was not more positive than the other conflicts. Post-hoc analysis revealed only one significant difference involving tone of coverage: that stories about "Desert Storm" were more positive toward the military than those about "Enduring Freedom" $\left(t_{151}=2.67, p<.05\right)$. Thus, $\mathrm{H} 3$ was not supported.

Although it was not predicted, the one-way ANOVA indicated a significant difference across conflicts in the extent of episodic framing $\left(F_{2,280}=8.52, p<.01\right)$. Post-hoc tests revealed that stories about "Iraqi Freedom" $\left(t_{196}=4.05, p<.01\right)$ and "Desert Storm" $\left(t_{153}=2.92, p<.05\right)$ employed more episodic frames than those about Operation "Enduring Freedom." However, mean differences between "Iraqi Freedom" and "Desert Storm" were not statistically significant.

\section{Discussion}

The U.S. military's decision to embed journalists in combat units during Operation "Iraqi Freedom" was unprecedented in its scope and 
a sharp contrast to past conflicts in which access of journalists was restricted. ${ }^{76}$ To date, however, there has been no systematic attempt to determine whether embedded coverage was different, either in form or tone. Some critics charged that embedded coverage would produce biased coverage, favoring the military. During Operation "Iraqi Freedom," one critic asserted that, "They're so embedded with the troops, they may as well be getting a P.R. retainer from the Pentagon. ${ }^{\prime 77}$ However, there had been no hard data on the effects of embedding ${ }^{78}$ beyond the personal opinions of journalists and academics.

This study anticipated that embedded coverage would produce more decontextualized coverage, manifesting itself in more episodic framing of stories. The results supported this expectation. Compared to nonembedded coverage, embedded journalists in Operation "Iraqi Freedom" produced news stories that featured more episodic frames. When stories about "Iraqi Freedom" were compared with those from "Desert Storm" and "Enduring Freedom," the results revealed more episodic framing in news reports about Operations "Iraqi Freedom" and "Desert Storm" compared to "Enduring Freedom." Stories about "Iraqi Freedom" appeared to feature more episodic framing than those from "Desert Storm," but differences in means were not statistically significant.

Iyengar argues that television, mainly because it is a visual medium that places a premium on exemplars, relies much more heavily on episodic framing. ${ }^{79}$ The results of this study indicate that the embedding of journalists in combat units in war is a special circumstance that produces the same effect, but with print journalism. When reporters are embedded, they produce stories that are more personalized, based on the experiences of the troops and the units covered. This is, indeed, a narrow slice, "a snapshot," 80 of the broader war, what Kaplan calls "vertical depth but little horizontal scope." ${ }^{11}$ In this sense, the results of this study replicate the experiences of the Falklands War, where embedding "led to an emphasis on the minutiae of the conflict at the expense of the big picture." 82 One consequence of increased focus on the "minutiae" of conflict is to lose sight of larger issues, in particular, war's purpose and the impact of specific operations on that broad design.

This study also anticipated that embedded reporting produces print news coverage that is more favorable in tone, both toward the military, generally, and toward its personnel in particular. This expectation was based on the fact that embedding makes journalists members, albeit temporarily, of individual military units. This allows journalists to come to know the troops they are covering and to internalize the values of the military unit they are embedded in.

The results supported this expectation. Results revealed that embedded coverage of "Iraqi Freedom" was more favorable in overall tone toward the military and in depiction of individual troops. However, despite the magnitude of the embedding employed in "Iraqi Freedom," it did not produce more positive coverage compared to recent conflicts. In fact, the only significant finding across conflicts was that the first five days of "Desert Storm" produced more positive coverage than did "Enduring Freedom." 
This positive bias can be explained by the fact that embedded journalists get to know the troops they are covering, producing increased levels of relational trust, ${ }^{83}$ coupled with the fact that journalists, especially in dangerous combat conditions, experience "swift trust," accepting, to some degree, the military's values. ${ }^{84}$ This finding confirms the hard evidence that "feelings of camaraderie" affected objectivity during the Falklands War, ${ }^{85}$ and supports anecdotal opinions of those journalists who argued that embedding carries the potential to bias coverage. ${ }^{86}$

Of course, bias is a double-edge sword. For the military, embedding provided a close-up view of combat operations that met all three of its possible motivations for implementing this strategy: it served as an effective counterbalance to enemy misinformation; it permitted news consumers to observe, first hand, the effectiveness of American fighting forces; and it provided a positive spin to news coverage. However, for the journalism establishment, embedding embodies a "professionally treacherous" reef. Journalists get to cover combat operations close up, giving them the access to combat operations that they want. But, in the process, they lose perspective and, thus, sacrifice the idealized standard of reporter objectivity. ${ }^{87}$

The results of this investigation simply indicate that embedding alters the nature and tone of coverage. These are the facts, which we hope will inform military public affairs decision making and journalist practices. A larger question concerns the practice of embedding in other reporting contexts (e.g., coverage of presidential campaigns, protest movements, terrorist groups, etc.) and whether it produces similar effects.

We posit one caveat about the results of this study. The coding was done by Department of Defense public affairs personnel, who were students in the Department of Defense Joint Course in Communication at the University of Oklahoma. Because of their military ties, coding may have been biased toward the military. However, coding was conducted under the direct supervision of the first author, their professor, and a doctoral student. In addition, any bias would have affected both embedded and nonembedded coverage, thus not undermining the main findings of this study.

\section{NOTES}

1. Secretary of Defense, "Public Affairs Guidance (PAG) for Movement of Forces into the CENTCOM AOR for Possible Future Operations" (position paper, Washington, DC, 3 February 2003).

2. Secretary of Defense, "Public Affairs Guidance."

3. Dale Eisman, "Clarke Discusses Revolution in War Reporting," Virginia Pilot, 3 June 2003, sec. A, p. 5, available at <http: / /80-wen.lexisnexis.com.ezproxy.lin.ou.edu.universe/ printdoc $>$.

4. Marvin Kalb, "Shoptalk: Journalists Torn between Purism and Patriotism," Editor \& Publisher, July 2003, 1-2, available at $<w w w . e d i t o r a n d p u b l i s h e r . c o m / e d i t o r a n d$ publisher features_columns/ article_display.js $\mid>$. 
5. Jennifer Harper, "Journalists Prepare to See War from the Battlefield," Washington Times, 4 March 2003, sec. A, p. 5.

6. Ellen Knickmeyer, "Military Prepares to Take Journalists into War," NAPA News.com, 8 March 2003, 1-3, available at $<w w w . n a p a n e w s . c o m / t e m p l a t e s /$ index.cfm? template $=$ story_full\&id=45AEFCD3-3675>.

7. Josh Getlin, "The War Beat: Will 'Embedding' Slant Reporting?" Seattle Times, 16 March 2003, pp. 1-4, available at <http:// seattletimes.nwsource.com $/ \mathrm{html} / \mathrm{iraq} / 134654470 \_w a r m e d i a 16 . \mathrm{html}>$.

8. Sarah Miskin, Laura Rayner, and Maria Lalic, "Media under Fire: Reporting Conflict in Iraq," Current Issues Brief Index, Department of the Parliamentary Library, Parliament of Australia, 24 March 2003, 1-26, available at <http://www.aph.gov.au/library/pubs/ CIB/2002=03/ 03bib21.htm>; Carol Brightman, "In Bed with the Pentagon," The Nation, 17 March 2003, 1-3, available at <www.thenation.com/ doc.mhtml?i=20030317\&s=brightman $>$.

9. Todd S. Purdum and Jim Rutenberg, "A Nation at War: The News Media; Reporters Respond Eagerly to Pentagon Welcome Mat," New York Times, 23 March 2003, sec. B, p. 3.

10. Secretary of Defense, "Public Affairs Guidance."

11. Purdum and Rutenberg, "A Nation at War," B3.

12. Doug Halonen, "The Pentagon Experiment: Spokesperson Clarke Documents Embed Process," Television Week, 19 May 2003, 18.

13. Sherry Ricchiardi, "Close to the Action," American Journalism Review, May 2003, 28-35.

14. Miskin, Rayner, and Lalic, "Media under Fire," 9. See David Morrison and Howard Tumber, Journalists at War (London: Sage Publications, 1988).

15. Miskin, Rayner, and Lalic, "Media under Fire," 4 and 9.

16. Miskin, Rayner, and Lalic, "Media under Fire," 4.

17. Terrence Smith, "The Real-Time War: Defining News in the Middle East," Columbia Journalism Review, May/June 2003, 1-8, available at <www.cjr.org/year $/ 03 / 3 /$ smith.asp $>$.

18. Smith, "The Real-Time War," 3.

19. Getlin, "The War Beat," 2.

20. Brightman, "In Bed with the Pentagon," 2.

21. Miskin, Rayner, and Lalic, "Media under Fire," 9.

22. Jim Ledbetter, "Two Cheers for Embedding: War Coverage Has Been High Tech and Low Calorie, but Don't Blame the Messengers," Time Europe, 7 April 2003, 1-3, available at <www.time.com/time/europe/ magazine/article/0,13005,901030407-438863,00.html >.

23. Jim Rutenberg and Bill Carter, "A Nation at War: The News Media; Spectacular Success or Incomplete Picture? Views of TV's War Coverage Are Split," New York Times, 20 April 2003, sec. B, p. 15.

24. Williamson Murray and Maj. Gen. Robert H. Scales, Jr., The Iraq War: A Military History (Cambridge, MA: The Belknap Press of Harvard University Press, 2003).

25. Erving Goffman, Frame Analysis (New York: Harper \& Row, 1974); Herbert J. Gans, Deciding What's News (New York: Vintage, 1979).

26. Gerald M. Kosicki, "The Media Priming Effect: News Media and 
Considerations Affecting Political Judgments," in The Persuasion Handbook: Developments in Theory and Practice, ed. James Price Dillard and Michael Pfau (Thousand Oaks, CA: Sage Publications, 2003), 63-81.

27. Zhongdang Pan and Gerald M. Kosicki, "Framing Analysis: An Approach to News Discourse," Political Communication 10 (February/ March 1993): 55-75; William A. Gamson and Andre Modigliani, "The Changing Culture of Affirmative Action," Research Annual in Political Sociology 3 (1987): 137-77; Vincent Price and David Tewksbury, "News Values and Public Opinion: A Theoretical Account of Media Priming and Framing," in Progress in Communication Sciences, ed. George A. Barnett and Franklin J. Boster (Norwood, NJ: Ablex, 1997), 481-506.

28. Price and Tewksbury, "News Values and Public Opinion," 175.

29. Shanto Iyengar, Is Anyone Responsible? How Television Frames Political Issues (Chicago: University of Chicago Press, 1991).

30. Iyengar, Is Anyone Responsible?, 14.

31. Shanto Iyengar, "Framing Responsibility for Political Issues," Annals of the American Academy 546 (July 1996): 59-70, 62.

32. Iyengar, Is Anyone Responsible?, 14.

33. Iyengar, "Framing Responsibility for Political Issues," 62.

34. Iyengar, "Framing Responsibility for Political Issues," 62.

35. Sherry Ricchiardi, "Preparing for War," American Journalism Review, 29 July 2003, 1-6, available at <http://www.ajr.org/ Article.asp?id=2794>.

36. Brightman, "In Bed with the Pentagon," 2.

37. Paul Friedman, "The Real-Time War: TV: A Missed Opportunity," Columbia Journalism Review, 29 July 2003, 1-7, available at http:// www.cjr.org/year/03/3/friedman.asp.

38. Robert D. Kaplan, "The Story of A War," Atlantic 292, November 2003, 161-62.

39. Kaplan, "The Story of A War," 161.

40. Murray and Scales, The Iraq War, 73.

41. Ledbetter, "Two Cheers for Embedding," 2.

42. Robert Jensen, "Embedded Media Give up Independence," The Boston Globe, 7 April 2003, sec. A, p. 19, available at <http:/ / 80-web.lexisnexis.ezprozy.lib.ou.edu/universe/printdoc $>$.

43. Miskin, Rayner, and Lalic, "Media under Fire," 9.

44. James S. Tyree, "How the War Was Covered: Embedding Provided Depth, not Breadth, Journalists Say," The Norman Transcript, 14 October 2003, sec, A, p. 1.

45. Irwin Altman and Dalmas A. Taylor, Social Penetration:The Development of Interpersonal Relationships (New York: Holt, Rinehart and Winston, 1973).

46. Dalmas A. Taylor, "Motivational Bases," in Self-Disclosure: Origins, Patterns, and Implications for Openness in Interpersonal Relationships, ed. Gordon J. Chelune and Associates (San Francisco: Jossey-Bass Publishers, 1979), 110-50.

47. Valerian J. Derlega, Sandra Metts, Sandra Petronio, and Stephen T. Margulis, Self-Disclosure (Newbury Park, CA: Sage, 1993).

48. Joseph Soeters, "Culture in Uniformed Organizations," in Handbook of Organizational Culture \& Climate, ed. Neal M. Ashkanasy, Celeste 
P. M. Wilderom, and Mark F. Peterson (Thousand Oaks, CA: Sage, 2000), 465-81.

49. Taylor, "Motivational Bases," 114.

50. A number of early studies consistently revealed positive associations between self-disclosure and liking. For a summary, see Taylor, "Motivational Bases," 122-23.

51. Lawrence R. Wheeless and Janis Grotz, "The Measurement of Trust and Its Relationship to Self-Disclosure," Human Communication Research 3 (spring 1977): 250-57.

52. Wayne E. Hensley, "A Theory of the Valenced Other: The Intersection of the Looking-Glass Self and Social Penetration," Social Behavior $\mathcal{E}$ Personality: An International Journal 24 (3, 1996): 293-308.

53. Edgar H. Schein, Organizational Culture and Leadership, $2 \mathrm{~d}$ ed. (San Francisco: Jossey-Bass, 1992), 12.

54. Michael Pacanowsky and Nick O'Donnell-Trujillo, "Organizational Communication as Cultural Performance," Communication Monographs 50 (June 1983): 126-47; Janice M. Beyer, David R. Hannah, and Laurie P. Milton, "Ties that Bind: Culture and Attachments in Organizations," in Handbook of Organizational Culture $\mathcal{E}$ Climate, ed. Neal M. Ashkanasy, Celeste P. M. Wilderom, and Mark F. Peterson (Thousand Oaks, CA: Sage, 2000), 323-338.

55. Schein, Organizational Culture and Leadership, 13.

56. Beyer, Hannah, and Milton, "Ties that Bind," 336.

57. Pacanowsky and O'Donnell-Trujillo, "Organizational Communication as Cultural Performance," 143.

58. Soeters, "Culture in Uniformed Organizations," 475.

59. Brightman, "In Bed with the Pentagon."

60. Soeters, "Culture in Uniformed Organizations."

61. Soeters, "Culture in Uniformed Organizations," 476.

62. Robert L. Heath and Jennings Bryant, Human Communication Theory and Research: Concepts, Contexts, and Challenges (Mahwah, NJ: Lawrence Erlbaum, 2000), 318.

63. Smith, "The Real-Time War," 3.

64. David Carr, "A Nation at War: The News Media," New York Times, 31 March 2003, sec. B, p. 2, available at <http:/ / www.nytimes.com>.

65. Ricchiardi, "Close to the Action," 30.

66. "Pros and Cons of Embedded Journalism," NewsHour Extra (27 March 2003): 1-3, availableat <www.pbs.org/newshour/extra/features/ jan-june03/embed_3-27.html>.

67. Miskin, Rayner, and Lalic, "Media under Fire," 12.

68. Morrison and Tumber, Journalists at War, 97.

69. Content analysis was based on the first five days of ground operations because the study examined coverage across three conflicts and one of them, Operation "Desert Storm," lasted only five days (100 hours).

70. Ole R. Holsti, "Content Analysis," in The Handbook of Social Psychology (vol. 2), ed. G. Lindzey and Elliot Aronson (Reading, MA: Addison-Wesley, 1968), 596-692.

71. Guido H. Stempel III and Bruce H. Wesley, eds., Research Methods in Mass Communication (Englewood Cliffs, NJ: Prentice-Hall, 1989). 
72. Intercoder reliability ratings across dependent measures were: for the overall tone of coverage $(n=120)$ : coder pair $1, .93$, and pair $2, .96$; for trust of troops $(n=80)$ : coder pair $1, .875$, and pair $2, .96$; and for episodic framing: coder pairs $1(n=10)$ and $2(n=11), 1.0$.

73. The measure was developed by Michael Burgoon and colleagues, "An Empirical Test of A Model of Resistance to Persuasion," Human Communication Research 5 (fall 1978): 27-39, and employed in a number of studies of political institutions. For a synthesis, see Patricia Moy and Michael Pfau, With Malice toward All: The Media and Public Confidence in Democratic Institutions (New York: Praeger, 2000).

74. Lawrence R. Wheeless and Janis Grotz, "The Measurement of Trust and Its Relationship to Self-Disclosure," Human Communication Research 3 (spring 1977): 250-57.

75. Charles Van Leer and Nick Trujillo, "On Becoming Acquainted: A Longitudinal Study of Social Judgment Processes," Journal of Social and Personal Relationships 3 (1986): 375-92.

76. Knickmeyer, "Military Prepares to Take Journalists into War"; Getlin, "The War Beat."

77. Walt Zwirko, "Embedded Journalists' Reporting Questioned," Dallas Morning News, 8 April 2003, pp. 1-3, available at < foi.missouri.edu/ jourwarcoverage/embeddedj.html $>$.

78. NewsHour Extra, "Pros and Cons of Embedded Journalism."

79. Iyengar, "Framing Responsibility for Political Issues," and Is Anyone Responsible?

80. Friedman, "The Real-Time War."

81. Kaplan, "The Story of A War," 161.

82. Miskin, Rayner, and Lalic, "Media under Fire," 9.

83. Hensley, "A Theory of the Valenced Other."

84. Soeters, "Culture in Uniformed Organizations," 476. Also, Brightman, "In Bed with the Pentagon."

85. Miskin, Rayner, and Lalic, "Media under Fire," 12.

86. Smith, "The Real-Time War"; Carr, "A Nation at War"; Ricchiardi, "Close to the Action"; NewsHour Extra, "Pros and Cons of Embedded Journalism."

87. Smith, "The Real-Time War," 3. 